APPENDIX II

\title{
PROGRESS IN THE DETERMINATION OF PHOTOVISUAL SEQUENCES AT THE HARVARD OBSERVATORY
}

Several years ago, the Harvard Observatory undertook the determination of the magnitudes of comparison stars for a number of variables, expressing them on the photovisual system (isochromatic plate and yellow filter). These magnitudes, intended for the use of visual observers, were published, with the corresponding charts, as Series VIII of the variable star charts of the Vatican Observatory.

The development of a satisfactory technique for the determination of photovisual sequences made it appear profitable to continue the work, and an extension is herein reported. The accompanying table lists sixty variable stars that were placed on the programme, and indicates the extent to which the work has been completed. For each variable star about fifteen comparison stars are measured, and if there are sequences published, or already in use, the stars that they contain have been chosen, so far as practicable. Each determination rests upon at least four good plates. Direct comparisons are made with the North Polar Sequence, and the final magnitudes are on the International System. The measures are being made by Dr Sergei Gaposchkin, who plans to publish the magnitudes of the comparison stars, and charts of the regions, in the near future. The determination of photovisual sequences for other variable stars will be continued on lines similar to the foregoing.

List of New Photovisual Sequences

\begin{tabular}{|c|c|c|c|c|c|}
\hline $\begin{array}{l}\text { RS And } \\
\text { VX And* } \\
\text { AC And* } \\
\text { RY Aql } \\
\text { WZ Aql } \\
\text { RW Aur } \dagger \\
\text { AG Aur } \\
\text { RT Cnc* } \\
\text { RV Cnc* } \\
\text { V CVn }\end{array}$ & $\begin{array}{l}\text { RV CVn } \\
\text { RT Cas* } \\
\text { RY Cas* } \\
\text { UV Cas* } \\
\text { VY Cas } \\
\text { VZ Cas* } \\
\text { BX Cas* } \\
\text { TZ Cep* } \\
\text { U Cyg } \\
\text { RV Cyg }\end{array}$ & $\begin{array}{l}\text { SZ Cyg } \\
\text { DF Cyg* } \uparrow \\
\text { CI Cyg } \\
\text { CE Cyg } \\
\text { CU Cyg* } \\
\text { EY Cyg } \dagger \\
\text { GY Cyg } \\
\text { RV Dra } \\
\text { UY Dra } \\
\text { RW Eri* }\end{array}$ & $\begin{array}{l}\text { SU Gem }{ }^{\prime} \\
\text { VY Her } \\
\text { AE Her } \\
\text { Z Lac* } \\
\text { TU Leo* } \\
\text { W LMi* } \\
\text { Z Lyn* } \\
\text { AY Lyr } \dagger \\
\text { RV Mon* } \\
\text { VW Oph }\end{array}$ & $\begin{array}{l}\text { BC Oph } \\
\text { BQ Ori* } \\
\text { CZ Ori } \\
\text { RU Peg } \dagger \\
\text { SW Peg } \\
\text { TW Peg } \\
\text { TX Peg } \\
\text { AF Peg } \\
\text { SY Per } \\
\text { TZ Per } \dagger\end{array}$ & $\begin{array}{l}\text { UZ Per } \\
\text { R Sge } \\
\text { V Sge } \\
\text { W Sge } \\
\text { RS Sge } \\
\text { RY Tau* } \\
\text { SU UMa*† } \\
\text { RY UMa† } \\
\text { TW Vrg } \\
\text { RU Vul }\end{array}$ \\
\hline
\end{tabular}

HaRLOW ShaPLEY 